\title{
Developmental Cellular Electrophysiologic Effects of Propafenone on the Rabbit Atrioventricular Node
}

\author{
KENNETH W. HEWETT, CHARLES H. GAYMES, CHUNG IL NOH, RENU HOLANI, AND \\ PAUL C. GILLETTE \\ Medical University of South Carolina, South Carolina Children's Heart Center, Division of Pediatric Cardiology, \\ Charleston, South Carolina 29425
}

\begin{abstract}
Transmembrane recordings and surface electrograms were used to evaluate the influence of propafenone on the cellular electrophysiology of isolated neonatal and adult rabbit atrioventricular node (AVN) preparations. An automatic interval of $863 \pm 82 \mathrm{~ms}$ (mean $\pm \mathrm{SEM}, n=$ 14) in neonates was found to be significantly shorter than the 1510- $\pm 205-\mathrm{ms}(n=12)$ automatic interval observed in adults. Propafenone in a concentration of $5 \times 10^{-6} \mathrm{M}$ significantly increased the automatic interval of neonatal pacemakers but not that of the adult preparations. These changes in automaticity produced by propafenone were not dependent on the adrenergic receptor-blocking action of the drug. The pacemaker escape time after overdrive pacing was also shorter in the neonate than in the adult. Propafenone prolonged the escape time of the neonatal tissues but not those of the adult. AVN refractory period, $\mathrm{A}-\mathrm{H}$ interval, and antegrade Wenckebach rate were comparably increased in a concentration-dependent manner in both age groups. The maximum diastolic potential was decreased by propafenone in the neonatal atrionodal tissue but not in other regions of the AVN and not in any region of the adult AVN. Action-potential duration was increased in all regions of the AVN in both age groups. Actionpotential amplitude and maximum upstroke velocity were decreased by propafenone in both age groups. Unlike other excitable tissues of the heart, the action-potential duration of AVN nodal cells increased with decreasing pacing intervals as the pacing interval approached the Wenckebach interval. This increase in action-potential duration was enhanced by propafenone and may be a major factor in the drug-dependent increase in the Wenckebach interval. These results may provide a partial explanation for the putative efficacy of propafenone in the treatment of junctional ectopic tachycardia in children. (Pediatr Res 32: 658-663, 1992)
\end{abstract}

\section{Abbreviations}

\section{AN, atrionodal}

AP-Amp, action-potential amplitude

$\mathrm{APD}_{50}$, action-potential duration at $\mathbf{5 0 \%}$ repolarization

$\mathrm{APD}_{90}$, action-potential duration at $\mathbf{9 0 \%}$ repolarization

AV, atrioventricular

AVN, atrioventricular node

HEG, His electrogram

HNH, high nodo-His

Received June 24, 1991; accepted July 30, 1992.

Correspondence and reprint requests: Kenneth W. Hewett, Ph.D., Medical

University of South Carolina, Division of Pediatric Cardiology, 171 Ashley Ave., Charleston, SC 29425.

Supported in part by Grant-in-aid 901073 from the American Heart Association.
MDP, maximum diastolic potential

$N$, nodal

$\dot{\mathrm{V}}_{\max }$, maximum action potential upstroke velocity

Propafenone is a relatively new and unique antiarrhythmic agent that has been shown to be effective in treating a wide variety of rhythm disturbances, including supraventricular tachycardias $(1,2)$ and Wolff-Parkinson-White syndrome (3), in adults. In children and infants, propafenone has been shown to be uniquely effective in treating junctional automatic tachycardia (4) and reentrant supraventricular tachycardia (5).

The mode of action of propafenone is unclear. This may be due in part to the drug's multiple electrophysiologic actions. Propafenone has been categorized as a class $1 \mathrm{c}$ agent because it decreases action-potential upstroke velocity and has a variable, dose-dependent effect on repolarization $(6,7)$. Propafenone is a strong sodium channel blocker (8) with use dependence (7) and, additionally, is a weak $\beta$-adrenergic receptor and calcium channel blocker (9). These latter two properties may be unimportant for most arrhythmias in adults, but in children they may be important. It has been shown in many experiments that the response to $\beta$-adrenergic blockers and $\beta$-adrenergic agonists is different in the immature heart when compared with adults (10-14). There is also evidence that the immature myocardium is more sensitive to the influence of calcium channel blockers than is adult tissue (15).

There is limited information about the electrophysiologic effects of propafenone on the AVN. Keller et al. (16) observed that $\mathrm{AV}$ conduction times in patients were increased by propafenone and that the increases correlated well with propafenone serum concentrations. Villafane et al. (17) found that the AV nodal functions of the intact newborn dog were depressed by propafenone as indicated by decreased pacing rates at which AV block occurred, increased refractory periods, and longer AV conduction times. Unfortunately, no parallel experiments with adult animals were done.

The purpose of these experiments was as follows: 1 ) to describe the cellular electrophysiologic effects of propafenone on the upper AV nodal (AN region), and midnodal fibers (N and $\mathrm{HNH}$ regions) of both the neonate and the adult rabbits; and 2) to determine the effects of propafenone on the functional properties of the AVN (automaticity, conduction time, refractory period, and antegrade Wenckebach interval) in the rabbit AVN in both age groups.

\section{MATERIALS AND METHODS}

Adult New Zealand White rabbits (approximately $2 \mathrm{~kg}$ in weight) were anesthetized with $60 \mathrm{mg} / \mathrm{kg}$ sodium pentobarbital 
by i.v. injection via the marginal ear vein. Neonates (animals $<10 \mathrm{~d}$ of age) were anesthetized via an intraperitoneal injection. The hearts were removed by midsternal thoracotomy and placed in cold Krebs buffer for dissection. The ventricle, below the AV ring, was removed and the right atrium was opened by making an incision through the AV ring and along the anterioseptal margin of the atrial wall and the superior vena cava. A pair of fine iris scissors were used to trim away excess atrial and ventricular myocardium from the AVN. The preparation was then placed, endocardial side up, in a small Lucite superfusion bath. Krebs solution (having the following composition in $\mathrm{mM}: \mathrm{NaCl}$, 126.5; $\mathrm{NaHCO}_{3}, 14.5 ; \mathrm{MgSO}_{4}, 1.2 ; \mathrm{KCl}, 2.6 ; \mathrm{KH}_{2} \mathrm{PO}_{4}, 1.2$ : $\mathrm{CaCl}_{2}, 2.7$; and glucose, 16) was saturated with $95 \% \mathrm{O}_{2}$ and $5 \%$ $\mathrm{CO}_{2}$ and warmed to $37 \pm 0.2^{\circ} \mathrm{C}$. This solution superfused the tissue at a flow rate of $12 \mathrm{~mL} / \mathrm{min}$. Bipolar silver wire electrodes were constructed from 34-gauge, Teflon-coated silver wire (Cooner Wire Co., Chatsworth, CA) having a nominal diameter of $0.152 \mathrm{~mm}$. The two wires were tightly twisted together so that the interelectrode distance was less than $0.5 \mathrm{~mm}$. Bipolar Tefloncoated silver wire electrodes were placed on the medial aspect of the coronary os for recording the atrial electrogram and on the lower portion of the node, immediately before it penetrated the fibrous ring, for recording the HEG.

Glass capillary microelectrodes, filled with $3 \mathrm{M} \mathrm{KCl}$ and having tip resistances of 15 to 25 megohms, were used to record transmission action potentials from the AVN. The microelectrode was attached to the headstage of a negative capacitance electrometer (KS-700, World Precision Instruments, Inc., New Haven, CT) through an $\mathrm{Ag}-\mathrm{AgCl}$ half-cell. $\mathrm{An} \mathrm{Ag}-\mathrm{AgCl}$ half-cell reference electrode was placed in the outflow path of the tissue chamber. The stimulus pulses were provided by a stimulus isolation unit (301, World Precision Instruments), which was driven at appropriate intervals by a custom-built microprocessorbased pulse generator. The stimuli were 1 to $2 \mathrm{~ms}$ in duration and the intensity was adjusted to $2 \times$ threshold. The amplified transmembrane signal was monitored on an oscilloscope, and selected data were digitized at $2 \mathrm{kHz}$ and stored on a microcomputer hard disk. The action-potential records were analyzed using a computer program that determined the activation voltage, peak overshoot, and MDP. The program then calculated the total APAmp, $\dot{\mathrm{V}}_{\max }$, and the $\mathrm{APD}_{50}$ and APD ${ }_{90} . \dot{\mathrm{V}}_{\max }$ was calculated using a first-difference approximation of the first time differential (18).

The preparations were allowed to recover for $1 \mathrm{~h}$ in the tissue bath before data were recorded. The criteria for an acceptable preparation was an A-H interval of less than $75 \mathrm{~ms}$ (in both age groups) and minimum Wenckebach intervals of less than 350 $\mathrm{ms}$ in both age groups. The basal automatic cycle interval of the subsidiary pacemaker site in the AVN preparation was measured more than 2 min after cessation of pacing. Ten to 15 spontaneous action potentials were used to derive an average. The escape time was measured by pacing the preparation at a basic cycle length of $400 \mathrm{~ms}$ for $1 \mathrm{~min}$. Then the stimulus was turned off and the time interval between the last stimulated beat and the first escape beat was measured.

Action-potential characteristics and refractory periods were measured at a basic cycle length of $600 \mathrm{~ms}$. The refractory period was determined by injecting an $S_{2}$ stimulus after every 10th $S_{1}$ response. The $S_{1}-S_{2}$ interval was decremented form $350 \mathrm{~ms}$ in 10 -ms steps until the $S_{2}$ conduction time became visibly prolonged, and then decremental steps were reduced to $5 \mathrm{~ms}$. The effective refractory period was defined as the minimum $S_{1}-S_{2}$ interval that was conducted through the AVN. The Wenckebach interval was determined by decrementing the pacing interval of a 1 -min pulse train by $10 \mathrm{~ms}$. The Wenckebach interval was verified by three separate measurements for each data point.

In the first eight experiments in each age group, after control measurements were made, the tissue was serially superfused with propafenone in concentrations of $1 \times 10^{-8}, 1 \times 10^{-7}, 1 \times 10^{-6}$, $5 \times 10^{-6}$, and $1 \times 10^{-5} \mathrm{M}$ for $40 \mathrm{~min}$ at each concentration. One, additional step was added to these initial experiments. In three experiments in both age groups, after control measurements, Krebs containing $1 \times 10^{-7} \mathrm{M}$ atenolol was superfused $30 \mathrm{~min}$ before propafenone and along with propafenone at each concentration.

It was clear from changes seen in the functional characteristics and in the action potentials in these initial experiments that in both age groups significant drug effect was first present at a concentration of $5 \times 10^{-6} \mathrm{M}$. However, at this drug concentration, most preparations remained sufficiently excitable to allow pacing at 400-ms intervals or less. Therefore, in a second series of experiments, concentrations of 0 (control) and $5 \times 10^{-6} \mathrm{M}$ propafenone were used.

Statistical methods. A two-way analysis of variance (BMDP, Los Angeles, CA) was used to determine whether there were significant differences between age groups. Differences between means were determined using a weighted $t$ test for separate variances and by applying Bonferroni's criteria for significance (19). All data are presented in text, tables, and figures as mean \pm SEM. A confidence interval of $95 \%$ was considered significant.

\section{RESULTS}

The three regions of the AVN that were studied in these experiments have been described previously, and these designations are based on the occurrence of the action-potential upstroke in the A-H interval (20). These are the AN, N, and $\mathrm{HNH}$ regions.

The $\beta$-adrenergic blocker atenolol produced no changes in either action-potential characteristics or functional parameters of the AVN in any of the experiments in which it was used. In addition, the effects of propafenone alone were indistinguishable from the effects of propafenone in conjunction with atenolol in all experiments (data not shown).

Drug-induced changes in AVN action potential. Two recordings of the type used in these experiments were superimposed in Figure 1 to demonstrate the effect of propafenone $\left(5 \times 10^{-6} \mathrm{M}\right)$ on the AVN electrophysiology. The transmembrane recordings were made through a microelectrode inserted into the $N$ region of an adult preparation. In other experiments, transmembrane recordings were made in the $\mathrm{AN}$ and $\mathrm{HNH}$ regions of both adult and neonatal AVN preparations. Two recordings, before and after drug, are aligned at the stimulus artifact (Figure 1, outlined arrow) to show that propafenone increases the conduction time

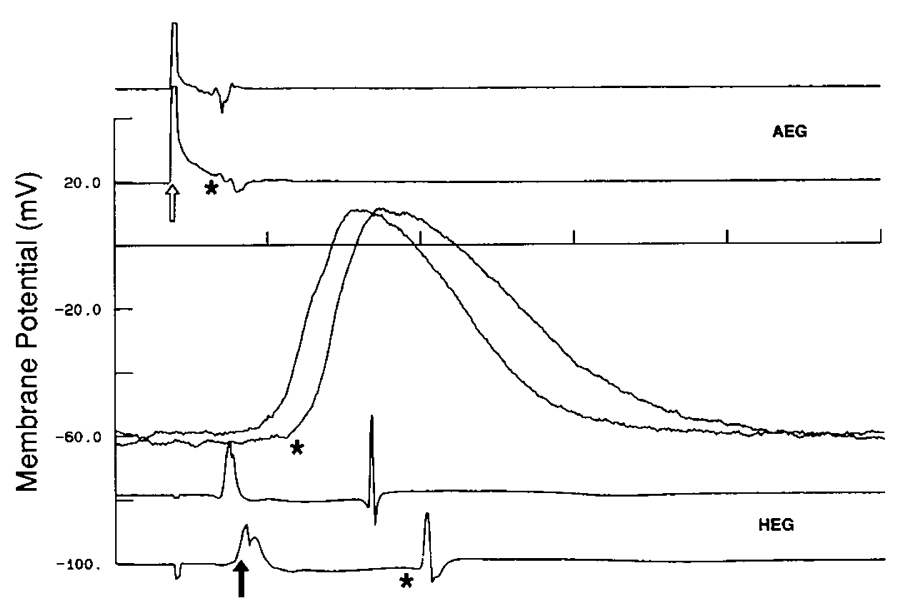

Fig. 1. Typical changes in the A-H interval and $\mathrm{N}$ cell action potential of an adult rabbit AVN. The asterisks indicate the drug tracings. The upper pair of tracings (atrial electrograms, $A E G$ ) are bipolar electrograms from the atrial myocardium adjacent to the AVN. The middle tracings are transmembrane recordings from the $\mathrm{N}$ region. The bottom pair of electrograms $(H E G)$ were recorded from this His bundle. The horizontal scale represents zero potential on the vertical scale, and the interval between tick marks on the horizontal scale indicates elapsed time of 60 $\mathrm{ms}$. The vertical scale represents $\mathrm{mV}$ for the transmembrane recording only. 
uniformly across the AVN. As was typical for these experiments, the amplitude of the atrial electrogram and to a lesser extent the HEG amplitude were decreased by propafenone. The deflections preceding the His spike in the HEG recordings (black arrow) represent electrotonic activity from the atrial or AN tissue adjacent to the His bundle. Propafenone had no effect on either APAmp or $\dot{\mathrm{V}}_{\max }$ in the $\mathrm{N}$ cell action potentials of either age group. This is illustrated in Figure 1. In these recordings, $\vec{V}_{\max }$ was unchanged by exposure to propafenone $(4.7 \mathrm{~V} / \mathrm{s}$ before drug and $5.3 \mathrm{~V} / \mathrm{s}$ after drug).

In Figures 2 and 3, the action-potential upstrokes, before and after drug, were approximated to show the effects of propafenone on the action-potential characteristics. The electrograms have been omitted for clarity. Control action-potential characteristics were the same between the age groups in all three AVN regions studied. Propafenone $\left(5 \times 10^{-6} \mathrm{M}\right)$ decreased MDP in the neonatal AN region but not in the adult. This was the only agerelated difference in the effect of propafenone on action potentials.

The effect of propafenone on the time course of repolarization was consistently increased in all regions of the AVN studied in both age groups (Figs. 1-3). These differences were found to be statistically significant in the $\mathrm{AN}, \mathrm{N}$, and $\mathrm{HNH}$ regions of both groups except $\mathrm{APD}_{50}$ of neonatal $\mathrm{N}$ cells (Table 1 ).

AN cell AP-Amp was significantly reduced in both age groups by propafenone, as was $\mathrm{V}_{\max }$ (Table 1). Figure 2 illustrates action potentials from the AN region of both neonatal (panel $A$ ) and adult (panel $B$ ) preparations. In the neonate, $V_{\max }$ was reduced from a control measurement of $28 \mathrm{~V} / \mathrm{s}$ to $16 \mathrm{~V} / \mathrm{s}$ after drug. Propafenone increased $\mathrm{APD}_{90}$ from 86 to $114 \mathrm{~ms}$. A similar reduction was seen in the adult tissue where $\dot{V}_{\text {max }}$ was decreased from 45 to $21 \mathrm{~V} / \mathrm{s}$ by propafenone. $\mathrm{APD}_{90}$ was increased from 79 to $131 \mathrm{~ms}$ by propafenone in this experiment.
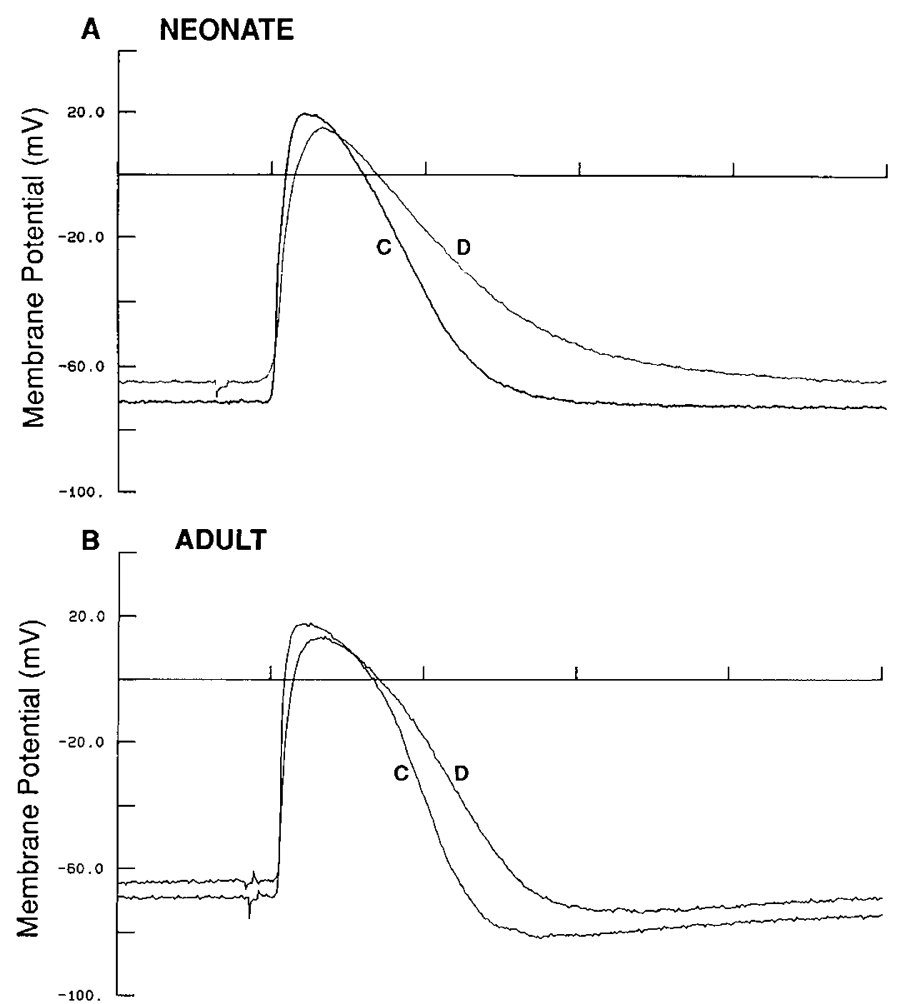

Fig. 2. Changes in AN cell action potentials with exposure to $5 \times$ $10^{-6} \mathrm{M}$ propafenone. Panel $A$ contains a control action-potential recording indicated by $C$ and drug recording signified by $D$. These action potentials were recorded in a neonatal preparation. Adult AN cell action potentials are shown in panel $B$ and the control and drug tracings are marked as in panel $A$. Horizontal tick marks indicate $60 \mathrm{~ms}$, and vertical markings indicate $\mathrm{mV}$.
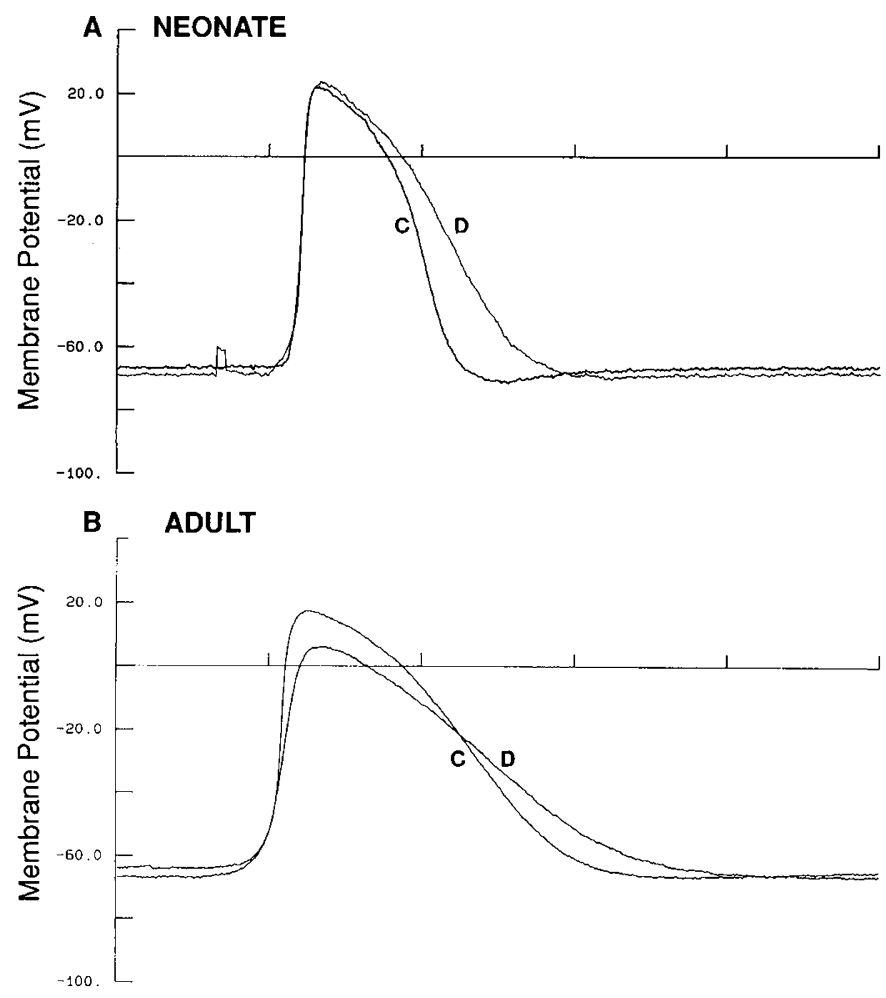

Fig. 3. Changes in $\mathrm{HNH}$ action potentials with exposure to $5 \times 10^{-6}$ $M$ propafenone. Panel $A$ contains a neonatal action potential before and after drug; panel $B$, adult action potentials. Markings are the same as in Figure 2.

Propafenone may significantly reduce the AP-Amp and the upstroke velocity in some but not all HNH cells. As shown in Figure 3 (panel $A$ ), the AP-Amp of this neonatal HNH cell action potential was unaffected by propafenone; in addition, $\dot{\mathrm{V}}_{\max }$ was unchanged or slightly increased from $9.5 \mathrm{~V} / \mathrm{s}$ during control measurements to $13 \mathrm{~V} / \mathrm{s}$ after drug. $\mathrm{APD}_{90}$ was increased from 74 to $107 \mathrm{~ms}$ by the drug in the experiment. AP-Amp in the adult HNH action potential (shown in panel $B$ ) was decreased as was $\dot{V}_{\text {max }}$ from 18.6 to $7.1 \mathrm{~V} / \mathrm{s}$ by propafenone. The average percentage of reduction in $\dot{\mathrm{V}}_{\text {max }}$ of the adult $\mathrm{HNH}$ action potentials produced by the drug was over $50 \%$ (Table 1 ); however, the high degree of variability in the control values and the response to drug may have prevented statistical significance from being reached. $\mathrm{APD}_{90}$ was increased by propafenone from 109 to 133 $\mathrm{ms}$ in this adult HNH cell.

Rate-dependent effects on $N$ cell action-potential duration. A characteristic of the $\mathrm{N}$ cell action potential that distinguishes it from other excitable tissue of the heart was the tendency for action-potential duration to increase rather than decrease as the pacing rate was increased. The increase in action-potential duration is particularly marked as the pacing interval approached the Wenckebach interval. Data from two experiments, one from each age group, are shown in Figure 4. The action-potential duration increased sharply at the fastest pacing rates to $A P D_{90}$ values of 150 to $160 \mathrm{~ms}$. Before drug administration, there was little rate-dependent increase in action-potential duration at pacing cycle lengths of $400 \mathrm{~ms}$ and greater. Propafenone increased the $\mathrm{APD}_{90}$ from control values at all pacing cycle lengths. In addition, the rate-dependence of $\mathrm{APD}_{90}$ at pacing cycle lengths greater than $400 \mathrm{~ms}$ was evident. Propafenone increased the maximal $\mathrm{APD}_{90}$ value when compared with the control.

Effects of propafenone on functional aspects of $A V N$. Functional characteristics are defined as automaticity, escape time, Wenckebach interval, refractory period, and conduction time (A-H interval). As we have previously shown (20), the control automatic interval is less in the neonatal rabbit AVN than it is in the 
Table 1. Effects of propaferone on adult and neonatal $A V N$ action potentials*

\begin{tabular}{|c|c|c|c|c|c|c|c|c|c|c|c|}
\hline \multirow{2}{*}{$\begin{array}{l}\text { AVN } \\
\text { region }\end{array}$} & \multirow[b]{2}{*}{ Age $\dagger$} & \multicolumn{2}{|c|}{$\begin{array}{l}\text { MDP } \\
(-\mathrm{mV})\end{array}$} & \multicolumn{2}{|c|}{$\begin{array}{c}\text { AP-AMP } \\
(\mathrm{mV})\end{array}$} & \multicolumn{2}{|c|}{$\begin{array}{l}\dot{\mathrm{V}}_{\max } \\
(\mathrm{V} / \mathrm{s})\end{array}$} & \multicolumn{2}{|c|}{$\begin{array}{c}\mathrm{APD}_{50} \\
(\mathrm{~ms})\end{array}$} & \multicolumn{2}{|c|}{$\begin{array}{c}\mathrm{APD}_{90} \\
(\mathrm{~ms})\end{array}$} \\
\hline & & $\mathrm{C}$ & $\mathrm{D}$ & $\mathrm{C}$ & $\mathrm{D}$ & $\mathrm{C}$ & D & $\mathrm{C}$ & $\mathrm{D}$ & $\mathrm{C}$ & $\mathrm{D}$ \\
\hline \multirow[t]{2}{*}{ AN } & $\mathrm{Neo}(7)$ & $68 \pm 2.2$ & $60 \pm 1.5 \neq$ & $99 \pm 2.3$ & $85 \pm 2.97$ & $64 \pm 16$ & $17 \pm 4.1 \ddagger$ & $63 \pm 7.7$ & $78 \pm 8.9 \ddagger$ & $85 \pm 10$ & $113 \pm 13 \neq$ \\
\hline & Ad (6) & $71 \pm 2.0$ & $69 \pm 2.1$ & $94 \pm 1.0$ & $88 \pm 1.4+$ & $26 \pm 7.5$ & $6.6 \pm 1.4 \ddagger$ & $53 \pm 3.3$ & $67 \pm 2.0 \ddagger$ & $82 \pm 1.1$ & $4.8 \neq$ \\
\hline \multirow[t]{2}{*}{$\mathrm{N}$} & Neo (5) & $62 \pm 2.1$ & $63 \pm 1.0$ & $82 \pm 7.1$ & $82 \pm 7.5$ & $5.9 \pm 1.7$ & $6.4 \pm 1.6$ & $79 \pm 2.1$ & $92 \pm 10.4$ & $111 \pm 12.2$ & $142 \pm 4.0 \ddagger$ \\
\hline & Ad (5) & $62 \pm 2.7$ & $63 \pm 2.1$ & $78 \pm 3.1$ & $76 \pm 4.9$ & $6.5 \pm 2.6$ & $6.4 \pm 2.1$ & $74 \pm 3.4$ & $90 \pm 7.3 \ddagger$ & $115 \pm 9.6$ & $150 \pm 12.6 \neq$ \\
\hline \multirow[t]{2}{*}{$\mathrm{HNH}$} & $\mathrm{Neo}(5)$ & $67 \pm 3.6$ & $65 \pm 2.2$ & $91 \pm 2.3$ & $87 \pm 6.5$ & $18.4 \pm 7.2$ & $11.1 \pm 4.9$ & $92 \pm 5.4$ & $111 \pm 8.5 \ddagger$ & $124 \pm 7.4$ & $161 \pm 11.17$ \\
\hline & $\operatorname{Ad}(5)$ & $67 \pm 5.8$ & $67 \pm 5.0$ & $93 \pm 6.5$ & $89 \pm 8.2$ & $36.4 \pm 24.1$ & $15.1 \pm 14.3$ & $85 \pm 10$ & $96 \pm 12+$ & $121 \pm 18$ & $144 \pm 15 \ddagger$ \\
\hline
\end{tabular}

* Measurements were made at basic cycle lengths of $600 \mathrm{~ms}$. C, control; D, drug; Neo, neonate; Ad, adult.

$\dagger$ Numbers in parentheses are the total number of experiments for that group.

$\$$ Indicates that control values differ significantly from drug values (propafenone $5 \times 10^{-6} \mathrm{M}$ ).

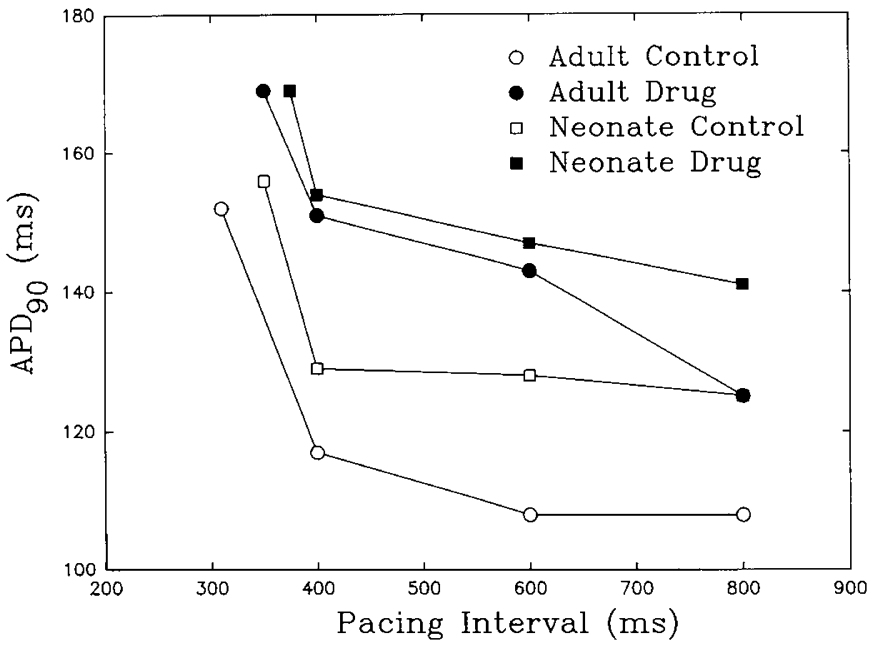

Fig. 4. Propafenone enhances rate-dependent increases in $\mathrm{N}$ cell action-potential duration during rapid pacing.

adult rabbit AVN (Table 2). In general, the pacemaker site is more atrial in the neonatal preparations than in the adults (20). In two of 14 adult preparations, spontaneous activity occurred first in the atrial electrogram, indicating a pacemaker site superior to the AVN. Pacemaker activity resided in the lower portion of the AVN in the other 12 adult preparations. Spontaneous activity originated above the $\mathrm{N}$ region in 11 of 15 neonatal preparations and in the lower or middle node in the remaining four preparations. As shown in Figure 5, the pre-drug (control) automatic interval in the neonatal preparations was significantly shorter than that in the adults. The neonatal automatic interval was significantly increased by $5 \times 10^{-6} \mathrm{M}$ propafenone. The adult AVN pacemaker was not affected at any concentration of propafenone. Automaticity was present in all preparations studied in both age groups. In three of 18 neonatal studies and one of 15 adult preparations, no overdrive suppression was observed. (Overdrive suppression is defined as having an escape time of at least three times the steady-state automatic interval.) The absence of overdrive suppression was interpreted to mean that pacemakers of these preparations were different from the other preparations and were excluded from the analysis of automaticity or escape time. The average automatic interval of these nonoverdriveable pacemakers in the neonate was $940 \pm 232 \mathrm{~ms}$, which was similar to the average automatic interval of the other preparations (Table 2). In all four preparations that failed to show overdrive suppression, the automatic interval after exposure to 5 $\times 10^{-7} \mathrm{M}$ propafenone was less than or unchanged from control.

The escape time of the neonatal pacemaker was significantly less than that of the adult (Table 2). After exposure to $5 \times 10^{-6}$ $M$ propafenone, the neonatal pacemaker escape time was increased, whereas the adult pacemaker escape time was unchanged.

Control refractory periods were the same in both adult and neonatal preparations and both were significantly increased at a propafenone concentration of $5 \times 10^{-6} \mathrm{M}$ (Table 2) but not at lower concentrations. The control antegrade Wenckebach interval was significantly greater in the neonatal group when compared with the adults. The effect of propafenone on the Wenckebach interval was similar in both age groups. As shown in Table 2 , there was a gradual increase in the Wenckebach interval,

Table 2. Effect of propafenone on functional characteristics of the AVN*

\begin{tabular}{|c|c|c|c|c|c|c|c|}
\hline & & $\mathrm{C}$ & $1 \times 10^{-8} \mathrm{M}$ & $1 \times 10^{-7} \mathrm{M}$ & $1 \times 10^{-6} \mathrm{M}$ & $5 \times 10^{-6} \mathrm{M}$ & $1 \times 10^{-5} \mathrm{M}$ \\
\hline \multirow[t]{4}{*}{ Escape time (s) } & $\mathrm{Ad}$ & (12) & (8) & (8) & (8) & (12) & (5) \\
\hline & & $20.5 \pm 5.6$ & $20.3 \pm 5.2$ & $18.8 \pm 4.8$ & $22.2 \pm 5.7$ & $22.96 \pm 4.7$ & $23.8 \pm 10.0$ \\
\hline & Neo & (13) & (7) & (7) & (7) & (13) & (6) \\
\hline & & $8.0 \pm 1.77 \dagger$ & $10.3 \pm 3.43$ & $12.3 \pm 3.39$ & $13.5 \pm 3.92$ & $14.1 \pm 4.2 \ddagger$ & $32.5 \pm 24.6$ \\
\hline \multirow[t]{4}{*}{ Refractory period (ms) } & Ad & $(13)$ & (7) & (7) & (7) & (13) & (7) \\
\hline & & $117 \pm 8.4$ & $112 \pm 14.0$ & $127 \pm 9.8$ & $107 \pm 83$ & $216 \pm 24.3$ & $265 \pm 41$ \\
\hline & $\mathrm{Neo}$ & (12) & (6) & (8) & (8) & (12) & $(6)$ \\
\hline & & $134 \pm 8.92$ & $141 \pm 11.9$ & $148 \pm 12.0$ & $154 \pm 9.3$ & $212 \pm 11.7$ & $384 \pm 120$ \\
\hline \multirow[t]{3}{*}{ A-H interval (ms) } & Ad & (11) & (7) & (7) & (7) & (11) & (7) \\
\hline & Neo & $\begin{array}{c}65.0 \pm 3.51 \\
(13)\end{array}$ & $\begin{array}{c}65.4 \pm 6.3 \\
(6)\end{array}$ & $\begin{array}{c}55.8 \pm 10.4 \\
(7)\end{array}$ & $\begin{array}{c}64.6 \pm 3.64 \\
(8)\end{array}$ & $\begin{array}{c}86.6 \pm 9.1 \\
\text { (13) }\end{array}$ & $\begin{array}{c}108 \pm 24.9 \\
(6)\end{array}$ \\
\hline & & $56.1 \pm 4.5$ & $56.0 \pm 9.5$ & $56.1 \pm 7.6$ & $60.2 \pm 6.5$ & $71.1 \pm 5.5$ & $86.6 \pm 15.2$ \\
\hline \multirow[t]{3}{*}{ Wenckebach interval (ms) } & Ad & (11) & (7) & (7) & (7) & (11) & (7) \\
\hline & & $250 \pm 12.2$ & $239 \pm 13.8$ & $247 \pm 15.2$ & $271 \pm 24.5$ & $377 \pm 29.6$ & $556 \pm 109$ \\
\hline & Neo & $\begin{array}{c}(12) \\
300 \pm 8.6\end{array}$ & $\begin{array}{c}(6) \\
300 \pm 18.8\end{array}$ & $\begin{array}{c}(8) \\
322 \pm 12.1\end{array}$ & $\begin{array}{c}(8) \\
331 \pm 4.6\end{array}$ & $\begin{array}{c}(12) \\
385 \pm 18.1\end{array}$ & $\begin{array}{c}(6) \\
516 \pm 89\end{array}$ \\
\hline
\end{tabular}

${ }^{*} \mathrm{C}$, control; Ad, adult; Neo, neonate. Numbers in parentheses represent the number of experiments.

$\uparrow$ Significantly different control value between age groups.

$¥$ Significantly different from adult value. 


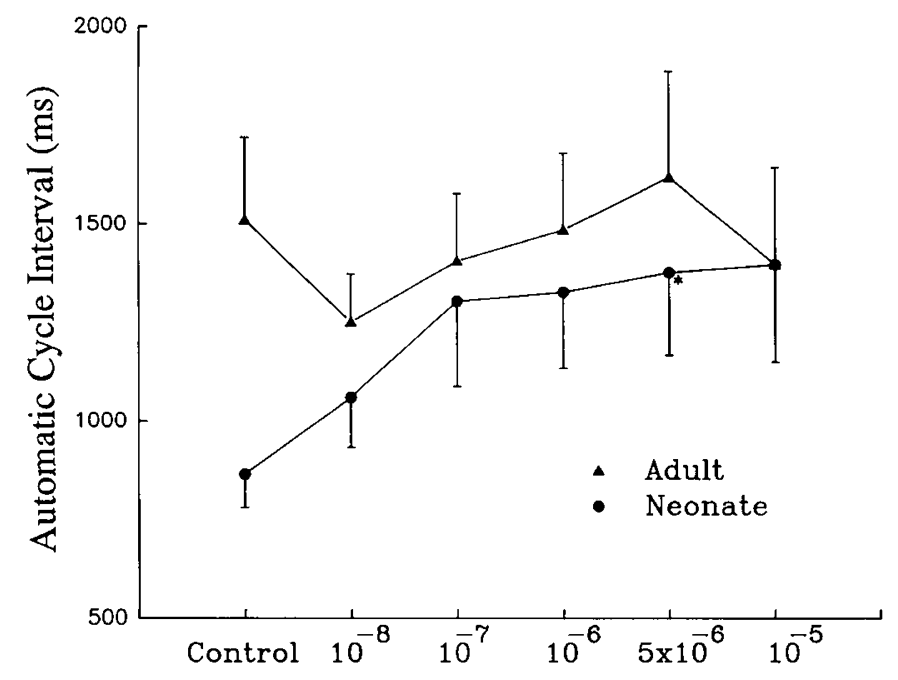

Fig. 5. The effect of propafenone on the automaticity of adult and neonatal AVN pacemakers. The total number of observations was eight at all concentrations except in the adult experiments, where $n=12$ for control and $5 \times 10^{-6} \mathrm{M}$ propafenone. The number of control and $5 \times$ $10^{-6} \mathrm{M}$ observations was 14 in the neonatal experiments. The asterisk indicates significant difference from control.

which reached significance at a concentration of $5 \times 10^{-6} \mathrm{M}$ in both age groups. The control conduction time (A-H interval) was not different between age groups. As in the Wenckebach interval and the refractory period parameters, propafenone gradually increased A-H interval, reaching statistical significance at the same concentration of $5 \times 10^{-6} \mathrm{M}$ (Table 2 ).

\section{DISCUSSION}

The AVN is a complex structure with heterogeneous electrophysiologic characteristics, as is indicated by the high degree of variability in action-potential shapes in various regions of the $\operatorname{AVN}(21,22)$. These differences in action-potential shape must reflect differences in membrane currents, which in turn are likely to result in different responses to antiarrhythmic drugs.

We have recently shown that there are not marked differences between the action potentials of individual regions of adult and neonatal rabbit AVN preparations (20). However, neonatal cardiac Purkinje fibers have been found to be affected differently by antiarrhythmic drugs when compared with adult tissues (2328 ). For this reason, we hypothesized that action potentials from one or more regions of the neonatal AVN would respond differently to an antiarrhythmic drug than would their adult counterparts. For the most part, tin the case of propafenone, that has not been found to be the case. The reduction of the MDP in the neonatal, but not in the adult, AN action potential was the only developmental difference seen in the effects of propafenone on the AVN action potentials.

The increase in action-potential durations found in all three regions and in both age groups were comparable to the concentration-dependent increase in action-potential duration produced by propafenone in most regions of the rabbit heart (6). Dukes and Vaughan-Williams (6) reported that propafenone decreased AP-Amp and $\dot{V}_{\max }$ in the sinus node, which has a low MDP and a very slow upstroke velocity much like the $\mathrm{N}$ cell action potential. The absence of any effect of propafenone on $\mathrm{N}$ cell action potentials show that there are significant electrophysiologic differences between $\mathrm{N}$ cell and sinus node action potentials. If it is assumed that propafenone primarily reduces the fast sodium current, these results suggest that there is significantly less fast sodium current in the $\mathrm{N}$ cell action-potential upstroke than in the sinus node potential. This idea is supported by Kreitner (29), who found that tetrodotoxin decreased sinus node action-potential upstroke velocity, and Zipes and Mendez (30), who showed that the fast sodium current blocker, tetrodotoxin, produced no change in $\mathrm{N}$ cell action potential.

From a clinical point of view, the most important result of these studies may be that propafenone suppressed steady-state automaticity and escape time in the neonatal AVN. Propafenone had no effect on either automaticity or escape time in the adult AVN. The finding that automaticity is suppressed by propafenone in the neonate may appear at odds with our other finding that maximum diastolic potential is also reduced by propafenone in the AN region in the neonate. We have found that the pacemaker site in the neonatal preparations are above (on the atrial side) of the $\mathrm{N}$ region of the AVN. If the pacemaker site were in the AN region of these preparations, the depolarizing effect of propafenone would be expected to enhance rather than suppress automaticity. In the absence of reliable data on the precise origin of pacemaker activity, we can only speculate that the pacemaker site is not typically in the AV region of these preparations.

Age-related differences in rate of automaticity and the influence of propafenone on pacemaker activity imply that there is a developmental change in the pacemaker currents. These agerelated effects of propafenone on automaticity are similar in two respects to a recent study from our lab. We found that bariuminduced abnormal automaticity in neonatal canine Purkinje fibers was more sensitive to the suppressive effect of propafenone than was abnormal automaticity in the adult preparations (31). Another parallel between these two studies is that in neonatal canine Purkinje fibers abnormal automaticity was more rapid than in the adult. Taken together, these results suggest that, irrespective of the type of tissue studied, pacemaker activity is more rapid in the neonate and more sensitive to propafenone. They also imply that there are developmental differences in pacemaker currents. It is also possible that these findings are, at least in part, the basis for the efficacy of propafenone in the treatment of junctional ectopic tachycardia in children (4).

The inability of $\beta$-adrenergic blockade with atenolol to influence the changes in functional parameters produced by propafenone, in particular automaticity, suggests that developmental differences in $\beta$-adrenergic receptor pharmacology were not responsible for the age-related differences in the effect of propafenone on automaticity.

The increase in action-potential duration of the $\mathrm{N}$ cell with rapid pacing has not to our knowledge been previously reported. Mendez and Moe (32) observed that very premature $S_{2}$ responses of $\mathrm{N}$ cells were prolonged. The prolongation of $\mathrm{N}$ cell action potentials with rapid pacing may result exclusively from the passive properties of the AN-N junction. Alternatively, the kinetics of one or more of the plateau currents involved in repolarization may be responsible. Our results show that $\mathrm{N}$ cell actionpotential prolongation occurs with rapid steady-state pacing and that propafenone enhances this effect.

The findings of these experiments can be summarized as follows: 1) propafenone decreases automaticity in neonatal but not adult rabbit AVN preparations; 2) conduction time, Wenckebach interval, and refractory period changes, in response to increasing concentrations of propafenone, were identical for both age groups; 3) action-potential duration was increased in all AVN regions in both age groups; 4) $\dot{\mathrm{V}}_{\max }$ and AP-Amp were decreased in the AN cell action potentials but not in the $\mathrm{N}$ cell action potentials; and 5) rate-dependent increases in $\mathrm{N}$ cell action-potential $\mathrm{APD}_{90}$ measurements are accentuated by propafenone.

Acknowledgments. The authors thank Kylie Martin for technical assistance during these experiments, Velma German for preparation of the manuscript, and Dr. Robert Reder of Knoll Pharmaceutical for generously supplying the propafenone used in these experiments. 


\section{REFERENCES}

1. Naccarella F, Bracchetti D, Palmieri M, Marchesini B, Ambrosioni E 1984 Propafenone for refractory ventricular arrhythmias: correlation with drug plasma levels during long-term treatment. Am J Cardiol 54:1008-1014

2. Coumel P, Laclercq JF, Assayag P 1988 European experience with antiarrhythmic efficacy of propafenone for supraventricular and ventricular arrhythmias. Am J Cardiol 54:60D-66D

3. Breithardt G, Borggrefe M, Wiebringhaus E, Seipel L 1984 Effect of propafenone in the Wolff-Parkinson-White syndrome: electrophysiologic findings and long-term follow-up. Am J Cardiol 54:29D-39D

4. Garson Jr A, Moak JP, Smith Jr RT, Norton Jr SB 1987 Usefulness of intravenous propafenone for control of postoperative junctional ectopic tachycardia. Am J Cardiol 59:1422-1424

5. Musto B, Donofrio A, Cavallaro C, Musto A 1988 Electrophysiological effects and clinical efficacy of propafenone in children with recurrent paroxysmal supraventricular tachycardia. Circulation 78:863

6. Dukes ID, Vaughan-Williams EM 1984 The multiple modes of action of propafenone. Eur Heart J 5:115-125

7. Honjo H, Watanabe T, Kamiya K, Kodama I, Toyama J 1989 Effects of propafenone on electrical and mechanical activities of single ventricular myocytes isolated from guinea-pig hearts. Br J Pharmacol 97:731-738

8. Kohlhardt M, Seifert C 1980 Inhibition of $\dot{V}_{\max }$ of the action potential by propafenone and its voltage-, time- and $\mathrm{pH}$-dependence in mammalian ventricular myocardium. Naunyn Schmiedebergs Arch Pharmacol 315:5562

9. Ledda F, Mantelli L, Manzini S, Amerini S, Mugelli A 1981 Electrophysiological and antiarrhythmic properties of propafenon in isolated cardiac preparations. J Cardiovasc Pharmacol 3:1162-1173

10. Horn EM, Johnson NJ, Bilezikian JP, Rosen MR 1989 Developmental changes in the electrophysiological properties and the $\beta$-adrenergic receptor-effector complex in atrial fibers of the canine coronary sinus. Circ Res 65:325-333

11. Feng Z-P, Dryden WF, Gordon T 1989 Postnatal development of adrenergic responsiveness in the rabbit heart. Can J Physiol Pharmacol 67:883-889

12. Truccone NJ, Spotnitz HM, Gersony WM 1975 Comparative cardiovascular effects of propranolol and practolol in puppies. Proc Soc Exp Biol Med 151:351-355

13. Young M-L, Fournier A, Stolfi A, Pickoff AS 1988 Electrophysiologic effects of intravenous propranolol in the intact immature mammalian heart. Dev Pharmacol Thera 11:125-134

14. Moak JP, Reder RF, Danilo Jr P, Rosen MR 1986 Developmental changes in the interactions of cholinergic and $\beta$-adrenergic agonists on electrophysiologic properties of canine cardiac Purkinje fibers. Pediatr Res 20:613-618

15. Chin TK, Friedman WF, Klitzner TS 1990 Developmental changes in cardiac myocyte calcium regulation. Circ Res 67:574-579
16. Keller K, Meyer-Estorf G, Beck OA, Hochrein H 1978 Correlation between serum concentration and pharmacological effect on atrioventricular conduction time of the antiarrhythmic drug propafenone. Eur $\mathrm{J}$ Clin Pharmacol 13:17-20

17. Villafane J, Gelband H, Xu H, McCormack J, Stolfi A, Pickoff AS 1987 The electrophysiologic effects of propafenone hydrochloride in the neonatal canine. Pediatr Res 22:50-54

18. Buckles DS, Hewett KW 1986 Assessment of the maximum frequency components and digital sampling of cardiac Purkinje fiber action potential. Comput Biomed Res 19:410-416

19. Wallenstein S, Zucker CL, Fleiss JL 1980 Some statistical methods useful in circulation research. Circ Res 47:1-9

20. Hewett KW, Gaymes CH, Noh C-I, Ross BA, Thompson RP, Buckles DS, Gillette PC 1991 Cellular electrophysiology of the neonatal and adult rabbit atrioventricular node. Am J Physiol 260:H1674-H1684

21. Billette $\mathrm{J} 1987$ Atrioventricular nodal activation during periodic premature stimulation of the atrium. Am J Physiol 252:H163-H177

22. Paes de Carvalho A, de Almeida DF 1991 Spread of activity through the atrioventricular node. Circ Res 8:801-809

23. Ezrin AM, Epstein K, Bassett AL, Myerburg RJ, Gelband H 1980 Effects of procaine amide on cellular electrophysiology of neonatal and adult dog myocardium. Dev Pharmacol Thera 1:352-363

24. Hamra M, Danilo Jr P, Rosen MR 1988 Developmental changes in the effects of nadolol on adult and neonatal canine Purkinje fibers. Dev Pharmacol Thera 11:155-165

25. Spinelli W, Danilo Jr P, Rosen MR 1988 Reduction of $\dot{V}_{\max }$ by QX-314 and Benzocaine in neonatal and adult canine cardiac Purkinje fibers. J Pharmacol Exp Ther 245:381-387

26. Jeck CD, Rosen MR 1990 Use-dependent effects of lidocaine in neonatal and adult ventricular myocardium. J Pharmacol Exp Ther 255:738-743

27. Spinelli W, Rosen MR 1986 Frequency-dependent actions of phenytoin in adult and young canine Purkinje fibers. J Pharmacol Exp Ther 238:794-801

28. Rosen MR, Hordof AJ, Hodess A, Verosky M, Vulliemoz Y 1975 Effects of ouabain on electrophysiologic properties of neonatal, young, and adult canine Purkinje fibers. J Pharmacol Exp Ther 194:255-263

29. Kreitner D 1985 Electrophysiological study of the two main pacemaker mechanisms in the rabbit sinus node. Cardiovasc Res 19:304-318

30. Zipes DP, Mendez C 1973 Action of manganese ions and tetrodotoxin on atrioventricular nodal transmembrane potentials in isolated rabbit hearts. Circ Res 32:447-454

31. Case CL, Ravin RR, Hewett KW, Gillette PC, Holani R 1990 Developmental effects of propafenone and its major metabolite on abnormal automaticity. Circulation 82 (suppl):224(abstr)

32. Mendez C, Moe GK 1966 Some characteristics of transmembrane potentials of AN nodal cells during preparation of premature beats. Circ Res 19:9931010 